NASA/TM-2003-212348

\title{
Toward a Dynamically Reconfigurable Computing and Communication System for Small Spacecraft
}

Muli Kifle, Monty Andro, Quang K. Tran, and Gene Fujikawa

Glenn Research Center, Cleveland, Ohio

Pong P. Chu

Cleveland State University, Cleveland, Ohio 
Since its founding, NASA has been dedicated to the advancement of aeronautics and space science. The NASA Scientific and Technical Information (STI) Program Office plays a key part in helping NASA maintain this important role.

The NASA STI Program Office is operated by Langley Research Center, the Lead Center for NASA's scientific and technical information. The NASA STI Program Office provides access to the NASA STI Database, the largest collection of aeronautical and space science STI in the world. The Program Office is also NASA's institutional mechanism for disseminating the results of its research and development activities. These results are published by NASA in the NASA STI Report Series, which includes the following report types:

- $\quad$ TECHNICAL PUBLICATION. Reports of completed research or a major significant phase of research that present the results of NASA programs and include extensive data or theoretical analysis. Includes compilations of significant scientific and technical data and information deemed to be of continuing reference value. NASA's counterpart of peerreviewed formal professional papers but has less stringent limitations on manuscript length and extent of graphic presentations.

- TECHNICAL MEMORANDUM. Scientific and technical findings that are preliminary or of specialized interest, e.g., quick release reports, working papers, and bibliographies that contain minimal annotation. Does not contain extensive analysis.

- CONTRACTOR REPORT. Scientific and technical findings by NASA-sponsored contractors and grantees.
- CONFERENCE PUBLICATION. Collected papers from scientific and technical conferences, symposia, seminars, or other meetings sponsored or cosponsored by NASA.

- SPECIAL PUBLICATION. Scientific, technical, or historical information from NASA programs, projects, and missions, often concerned with subjects having substantial public interest.

- TECHNICAL TRANSLATION. Englishlanguage translations of foreign scientific and technical material pertinent to NASA's mission.

Specialized services that complement the STI Program Office's diverse offerings include creating custom thesauri, building customized databases, organizing and publishing research results ... even providing videos.

For more information about the NASA STI Program Office, see the following:

- Access the NASA STI Program Home Page at http://www.sti.nasa.gov

- E-mail your question via the Internet to help@sti.nasa.gov

- Fax your question to the NASA Access Help Desk at 301-621-0134

- Telephone the NASA Access Help Desk at 301-621-0390

- Write to:

NASA Access Help Desk

NASA Center for AeroSpace Information 7121 Standard Drive

Hanover, MD 21076 
NASA/TM-2003-212348

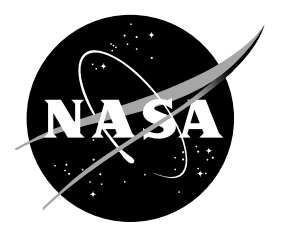

\section{Toward a Dynamically Reconfigurable Computing and Communication System for Small Spacecraft}

Muli Kifle, Monty Andro, Quang K. Tran, and Gene Fujikawa

Glenn Research Center, Cleveland, Ohio

Pong P. Chu

Cleveland State University, Cleveland, Ohio

Prepared for the

21st International Communication Satellite System Conference (ICSSC) and Exhibit cosponsored by the American Institute of Aeronautics and Astronautics and the Institute of Electronics, Information and Communication

Yokohama, Japan, April 15-19, 2003

National Aeronautics and

Space Administration

Glenn Research Center 
Available from

NASA Center for Aerospace Information 7121 Standard Drive

Hanover, MD 21076
National Technical Information Service 5285 Port Royal Road Springfield, VA 22100

Available electronically at http://gltrs.grc.nasa.gov 


\title{
TOWARD A DYNAMICALLY RECONFIGURABLE COMPUTING AND COMMUNICATION SYSTEM FOR SMALL SPACECRAFT
}

\author{
Muli Kifle, Monty Andro, Quang K. Tran, and Gene Fujikawa \\ National Aeronautics and Space Administration \\ Glenn Research Center \\ Cleveland, Ohio 44135 \\ Pong P. Chu \\ Cleveland State University \\ Cleveland, Ohio 44115
}

\begin{abstract}
$\underline{\text { Abstract }}$
Future science missions will require the use of multiple spacecraft with multiple sensor nodes autonomously responding and adapting to a dynamically changing space environment. The acquisition of random scientific events will require rapidly changing network topologies, distributed processing power, and a dynamic resource management strategy. Optimum utilization and configuration of spacecraft communications and navigation resources will be critical in meeting the demand of these stringent mission requirements. There are two important trends to follow with respect to NASA's (National Aeronautics and Space Administration) future scientific missions: the use of multiple satellite systems; and the development of an integrated space communications network. Reconfigurable computing and communication systems may enable versatile adaptation of a spacecraft system's resources by dynamic allocation of the processor hardware to perform new operations or to maintain functionality due to malfunctions or hardware faults. Advancements in FPGA (Field Programmable Gate Array) technology make it possible to incorporate major communication and network functionalities in FPGA chips and provide the basis for a dynamically reconfigurable communication system. Advantages of higher computation speeds and accuracy are envisioned with tremendous hardware flexibility to ensure maximum survivability of future science mission spacecraft. This paper discusses the requirements, enabling technologies and challenges associated with dynamically reconfigurable space communications systems.
\end{abstract}

Background

Communication system architectures with multiple small spacecraft are being planned to realize the science required for future NASA missions. This emerging trend of multiple spacecraft architecture holds advantages over a single large spacecraft because of its distributive processing nature, and the adaptability of the system to meet the evolving needs of the missions. Large, single-spacecraft systems (such as Hubble Space Telescope) have nearly reached the fundamental limit in image resolution attainable by such systems, and thus new architectures have to be created to meet the demands of future science missions. Using collaboration of multiple spacecraft enables greater resolution, improves remote sensing performance, and provides robustness over current implementations [1].

The future architectures of multi-spacecraft systems can be classified into a number of configurations $[2,3]$ :

- Well-defined constellations of nodes orbiting a celestial body like Earth or Mars forming a network of sensors with inter-satellite links and/or relay communications hubs.

- Fixed formation flyers of cooperating nodes, configurable in fixed symmetrical geometries; free flying nodes (or self-organizing sensor nodes) that organize to observe and measure events in real time.

- Ultra small free flying sensor nodes that form ad-hoc networks for monitoring events. Reconfiguring the cluster geometry will allow multiple mission sets to be performed.

Figure 1 depicts various multiple spacecraft systems and their configurations 


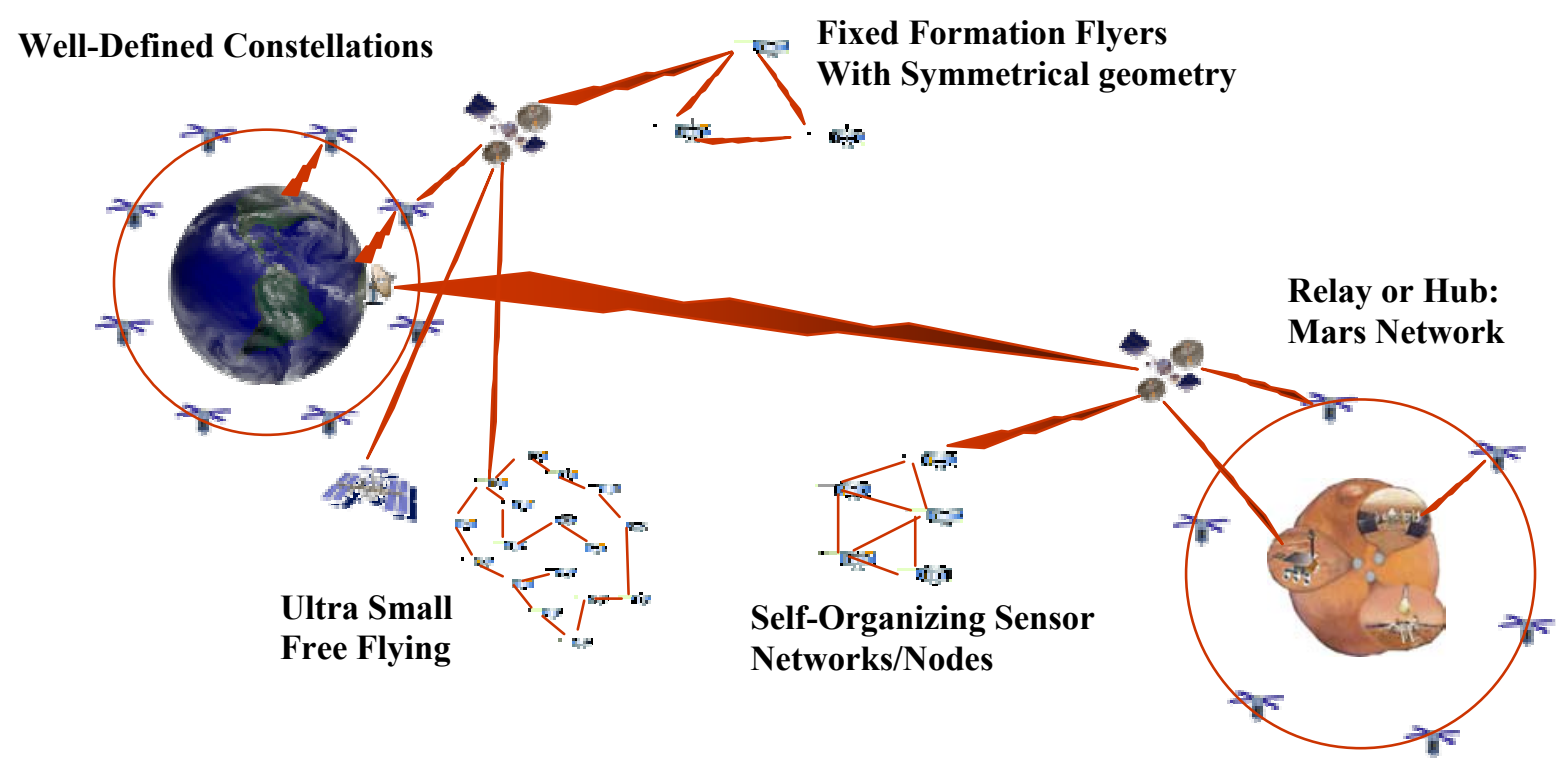

Figure 1: Multi-Spacecraft System Architectures and Configurations

$\underline{\text { Future Mission Requirements and Technology }}$ Challenges

Due to the varying degrees of dynamic behavior of these multi-spacecraft systems, robust and adaptable communications will play a critical role in the realization of these future architectures.

Reconfigurable technologies need to be developed to meet the stringent control and performance requirements of the missions. Some of the projected requirements of such systems may include:

- Multi-hop capabilities for intelligent innetwork aggregation and distribution

- $\quad$ Rapid adaptation to changing network topology while maintaining robust communications

- Autonomous, adaptable bandwidth utilization to constantly meet varying link conditions and data throughput requirements

- Agile/adaptable communication links for legacy and future mission interoperability

- Passive communications (sleep-mode) for reduced power usage

- Optimize channel capacity to increase reliability and to improve quality of service

- Multiple communication channels and protocols per nodes

- Adapt and optimize protocols for each environment and situation
- Ability to fully support time synchronization and position awareness

- Shared communication medium with multiple access capabilities

- Hardware management and dynamic allocation of resources

Component technologies need to be developed to realize robust and adaptable communication systems:

- Smart, conformal antennas to support multiple beam patterns and shapes

- Matched RF (Radio Frequency) and antenna systems with digital compensation for freespace signal combining for multi-array communications

- Adaptive and agile beam forming, steering, and tracking

- $\quad$ Agile RF front ends

- Optical communication transceivers for extremely high data rates

Other core technology challenges identified by NASA for realizing the future missions include on-board processing, intelligent platform control, network configuration, and data distribution and storage $[4,5]$ :

- On-Board Processing and Intelligent Sensor Control: Self re-configurable processors, or adaptive computers, have their configurations changed as the environment in which they are operating changes, as mission requirements 
evolve, and as algorithms are modified or replaced. This would greatly enhance a system's flexibility and performance over the lifetime of a mission.

- Intelligent Platform Control: Autonomous spacecraft control allows platforms to adjust their positions in space relative to the constellation of sensors in response to new science opportunities and collaborative data gathering.

- High Data Transmission and Network Configuration: The greatest challenge to reconfigurable computing and communication technology will be establishing and maintaining a viable communication network among a constellation of satellites operating in diverse orbits. It is anticipated that the demand for increased throughput will increase at a greater rate than available bandwidth, regardless of the transmission technology used. Other technologies that increase data transmission throughput that will play an important role in implementing high-speed data links are new bandwidth and power efficient modulation and coding techniques, high performance electronically steered antenna systems, and adaptive /configurable network and radio architectures, and optical communications.

- Data and Information Production, Distribution and Storage: The software technologies that simplify the manipulation of data will be needed, such as feature extraction/change detection, and algorithms that permit dynamic interaction and human-centric interaction.

\section{$\underline{\text { Reconfigurable Computing And Communication }}$ $\underline{\text { Technologies }}$}

Reconfigurable computing addresses the increased demand of computations in space, resulting from the use of more complex algorithms necessary to acquire, process, and transmit data, and the desire to change/adapt the on-board processing algorithms or mission objectives in real-time [6]. Reconfigurable computing technology is currently being used in a number of targeted markets, but there are limitations based on the chosen technology:

- GPP (General Purpose Processor) is designed to provide a class of functionality and not for a special function. It is difficult for GPP to get an exact mapping to utilize all the resources optimally in a specialized application.

- DSP (Digital Signal Processor) has the ability to be reprogrammed at will and perform complex algorithms reliably, but the multiple machine cycles per high-level language instruction limits processing bandwidth.

- $\quad$ ASIC (Application Specific Integrated Circuit) has the advantage of much wider bandwidth, but is limited by long development cycles, large costs, and inflexibility once deployed.

- $\quad$ RHW (Reconfigurable Hardware) can be configured to provide special functionality and provide better performance than a corresponding processor based solution. Flexibility, design effort and cost make RHW solution more acceptable than a corresponding ASIC based solution.

The successful advancements in field programmable systems are pointing towards an emerging technology of dynamically reconfigurable systems. The promise of architectures that can be altered "on the fly" according to prevailing conditions, adds a new dimension to the design of real-time systems. A dynamically reconfigurable system is one that changes its "form" in order to alter its function. To be "dynamically reconfigurable" it must be possible to change its function during operation, or by taking it out of service for a brief moment. There are different approaches for how systems can be reconfigured in terms of granularity, the intelligence and the control method required. Current technology still cannot support a fully reconfigurable system. FPGA is a viable, but not ideal, implementation technology. Since it is well developed, present FPGA technology is a viable nearterm solution. In the long term, new device technology, such as evolvable hardware, will be exploited to construct a fully functional, reconfigurable system.

\section{FPGA technology: Present or Short-term Solutions}

Because of field programmability, capacity and radiation-hardness, FPGA technology is becoming more and more, a suitable candidate for space-based applications. In the past, programmable devices are normally used as "glue logic" for large components. However, recent advancements improve the density of the device and make it possible to construct sophisticated systems entirely using FPGA chips. It seems possible to utilize FPGA technology to incorporate functions of data link layer, network layer, transport layer and channel coding and decoding sublayer and modulation and demodulation sublayer. One or more FPGA chips can be used to replace the general purpose processor, DSP processor, ASSP (Application Specific Signal Processor) and ASIC components, as shown in Figure 2. 


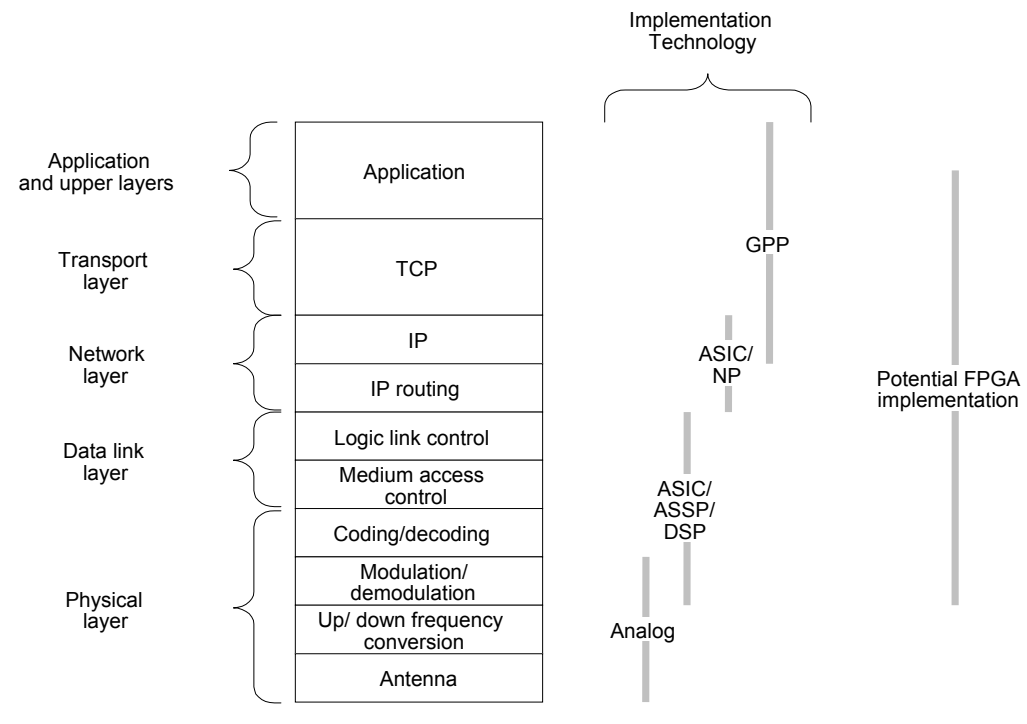

Figure 2: Layer Model and Implementation Technology

The reconfigurability of FPGA technology offers tremendous advantages for space-based applications. The major potential benefits include:

- Fabrication Cost: Unlike an ASIC, which has to be fabricated in a special facility, FPGA based design can be constructed by configuring the SRAM in the field and involves no non recurring engineering cost. This is very important for space based applications since the volume of demand is relatively small.

- Resource sharing: Since an FPGA chip can be configured to different functions, the hardware can be shared by different applications in a "time-multiplexed" fashion. For example, the same chip can be first configured for data processing and then configured as a communications system to transmit the result to a ground station. It is also possible to configure the same chip for either intra-network communication (like LAN) or inter-network communication (between spacecraft and ground station). Since the weight and power of a small spacecraft are severely constrained, resource sharing will be extremely beneficial.

- Adaptability: Since the FPGA can be reconfigured in the field, the circuit can be modified to meet the new mission need or to react to unforeseen events. It can also make the communications system backward compatible (i.e., be compatible with existing system that is still in service) or "forward compatible" (i.e., be compatible with future protocols).

- Upgradeability: Unlike ASIC or ASSP, whose functionality is fixed when fabricated, the FPGA can be upgraded in the field later when a new, more efficient algorithm or scheme is developed.

- COTS (Commercial-Off-The-Shelf) availability: The choice of commercial spacequalified, radiation hardened parts is very limited. The design becomes more difficult as number of components in a system increases. Since an FPGA chip is a "generic" device that can be configured to a variety of functions, only one radiation hardened component needs to be developed. Currently, radiation hardened FPGA parts are available from various FPGA manufacturers $[7,8]$.

Unlike space-based applications, there are wide varieties of components and technologies to choose from for terrestrial implementation and new parts are continuously being developed for new functionalities and new applications. Unfortunately, most of these COTS components including some FPGA chips cannot be used in space-based applications. In space, highenergy particles are introduced from galactic cosmic rays and solar flares and are encountered by the electronics as a spacecraft passes through the Earth's radiation belts. Today's sophisticated electronic 
devices are sensitive to these kinds of radiation and a non-space qualified part will be damaged and malfunction while exposed in this environment $[9,10$, 11]. Thus, the advanced FPGA chips, which have fastest clock speeds and higher density, are unsuitable for space missions. To overcome the radiation, special design techniques and fabrication processes have to be used. Developing a space-qualified, radiation-hardened component is difficult and costly. Also, because of the small volume of demand for space-qualified devices, the demand for these components is far less than their terrestrial counterparts. A few radiation-hardened components and some FPGA devices have been developed $[7,8,9]$, but there is a significant gap between the electronics fabricated for space and the state of the art technology. There is typically a 3-to-6 year gap between a state of the art (SOA) digital component and its space qualified counterpart because of the radiation-hardened requirement for space applications. The very limited choice of SOA electronic parts imposes a severe constraint on the design and implementation of a space-based communications system.

There are limitations to present FPGA technology. FPGA is designed to be electrically reprogrammable, allowing embedded systems to be modified or upgraded in the field without physical replacement of hardware components [12]. The most flexible form of the FPGA uses SRAM-based technology to store look-up tables characterizing both cell function and interconnection. The memory elements defining the logic functions, memory characteristics, connections and other parameters must be filled with appropriate data values for basically fixed designs. This means that programming the chip's functions amounts to writing data into memory address. The disadvantage is that there must be continuous power supplied so that the memory retains its contents, or facility for download from PROM at power-up. Time taken to program an FPGA varies according to size and technology, but is on the order of a second. Thus, reconfiguring an FPGA requires more hardware, and taking more processing time, simply by storing several different fixed designs in ROM and downloading as required.

$\underline{\text { Evolvable Hardware Technology: Long-Term Solutions }}$

Recall that the most critical feature of a dynamically reconfigurable system is one that changes its form in order to alter its function. Dynamically reconfigurable hardware technology such as "evolvable hardware"refers to hardware design and self-reconfiguration using evolutionary and genetic mechanisms [13]. The application of evolution-inspired hardware design and self-configuration lead to the concept of evolvable hardware. In a broader sense, evolvable hardware refers to various forms of hardware from sensors and antennas to complete evolvable space communication systems that could adapt to changing environments and, moreover, increase their performance during their operational lifetime [14].

Although evolvable hardware is still in its infancy, a number of useful areas of space applications have already been identified. Evolvable hardware has the potential to adapt autonomously to changes in its environment. This will be very useful for situations where real-time control over systems by humans is not possible, such as on deep space missions or when harsh or unexpected conditions are encountered. An autonomous spacecraft, which will able to cope with problems for which solutions were not specified on ground and will able to adapt itself to new or changing environment, plays a key role in future missions. Possible applications include: relay-type satellite; formation flying satellite; relay ad hoc networks; static sensor networks; self-organizing sensor networks; dynamic sensor networks; and mobile sensor and observer. There is a wealth of research activities to determine the feasibility and applicability of the evolvable hardware-based space systems. For example, self-organizing sensor networks may be built from sensor nodes that may spontaneously create impromptu networks, assemble the network themselves, dynamically adapt to device failure and degradation, manage movement of sensor nodes, and react to changes in task and network requirements [15]. Selforganizing sensor networks can be built using evolvable hardware-based smart sensor nodes that enable sensor devices to be self-aware, reconfigurable and autonomous. Thus, some of the benefits realized by evolvable hardware-based space applications include: flexibility and adaptability; real-time responses; reduction in costs; simplified hardware complexity; system interoperability; and self-repair and healing.

\section{Summary}

Dynamically reconfigurable hardware technology such as evolvable hardware is an ideal long term solution to enable adaptation of multiple spacecraft system resources. Its unique capabilities allow new operations or new functionality in the event of malfunctions or hardware faults occurring elsewhere in the communication or sensor systems. This feature makes it a very promising technology for missions where realtime control over systems by humans is not possible, such as on deep space missions or when harsh or unexpected conditions are encountered. Dynamically reconfigurable hardware will become an enabling 
technology to meet the requirements of these future missions. In addition, dynamically reconfigurable computing and communication systems can take advantage of optimization of resources. Flexibility of hardware configurations and robustness through adaptability are key features that multiple spacecraft systems can capitalize on. Even today, the advancements in FPGA technology make it possible to incorporate some communication and network chip functionality and provide the basis for a dynamically reconfigurable system. However, due to the present limitations of FPGA technology, future missions will require the pursuit of advanced technology in selfreconfigurable and evolvable hardware.

\section{$\underline{\text { References }}$}

1. Leitner, J., Bauer, F., Folta, D., Carpenter, R., Moreau, M., How, J. - Formation Flying in Space - Distributed Spacecraft Systems Develop New GPS Capabilities, GPS World, Feb. 2002.

2. Chien-Chung Shen, et.al, "Interrogation-Based Relay Routing for Ad hoc Satellite Networks," University of Delaware, Feb. 2002.

3. Bhasin, K., et.al, "Advanced Communication and Networking Technologies for Mars Exploration, "NASA TM 2001.

4. Prescott, G., Smith, S., and Moe, K., "Information System Technology Challenges for NASA's Earth Science Enterprise", NASA TM 2001.

5. Prescott, G., "Real-Time Information System Technology Challenges for NASA's Earth Science Enterprise," NASA TM 2001.

6. The New Frontier: reconfigurable computing, Military \& Aerospace Electronics, May 2002.

7. Carmichael, C., "SEU Mitigation Techniques for Virtex FPGAs in Space Applications", Military Application of PLD Conference, 1999.

8. Fabula, J. and Bogrow, H., "Total Ionizing Dose Performance of SRAM-based FPGAs and supporting PROMs", Military Application of PLD Conference, 2000.

9. Katz, R., et al., "Radiation Effects on Current Field Programmable Technologies", IEEE Transactions on Nuclear Science, Dec. 1997.

10. Sexton, F.W., et. al., "Qualifying commercial ICs for space total dose environments," IEEE Trans. On Nuclear Science, Dec. 1992.

11. Stassinopoulos, E.G. and Raymond, J.P., "The Space Radiation Environment for Electronics," Proceedings of IEEE, Nov. 1988.

12. Carter, A., "Using Dynamically Reconfigurable Hardware in Real-Time Communications Systems," Literature survey by University of York, Nov. 2001.
13. Fukunaga, A., Hayworth, K., Stoica, A., "Evolvable Hardware for Spacecraft Autonomy," Proceedings of IEEE, 1998.

14. Stoica, A., "Evolvable Hardware: From On-Chip Circuit Synthesis to Evolvable Space Systems", IEEE, 2000.

15. Lim, A., "Distributed Services for Information Dissemination in Self-Organizing Sensor Networks", Special Issue on Distributed Sensor Networks for Real-Time Systems with Adaptive Reconfiguration, Journal of Franklin Institute, Vol. 338, 2001. 
Public reporting burden for this collection of information is estimated to average 1 hour per response, including the time for reviewing instructions, searching existing data sources, gathering and maintaining the data needed, and completing and reviewing the collection of information. Send comments regarding this burden estimate or any other aspect of this collection of information, including suggestions for reducing this burden, to Washington Headquarters Services, Directorate for Information Operations and Reports, 1215 Jefferson Davis Highway, Suite 1204, Arlington, VA 22202-4302, and to the Office of Management and Budget, Paperwork Reduction Project (0704-0188), Washington, DC 20503.

\begin{tabular}{|l|l|l|}
\hline 1. AGENCY USE ONLY (Leave blank) & $\begin{array}{c}\text { 2. REPORT DATE } \\
\text { June } 2003\end{array}$ & $\begin{array}{r}\text { 3. REPORT TYPE AND DATES COVERED } \\
\text { Technical Memorandum }\end{array}$ \\
\hline
\end{tabular}

\section{TITLE AND SUBTITLE}

Toward a Dynamically Reconfigurable Computing and Communication System for Small Spacecraft

\section{AUTHOR(S)}

Muli Kifle, Monty Andro, Quang K. Tran, Gene Fujikawa, and Pong P. Chu

\section{FUNDING NUMBERS}

WBS-22-704-60-14

\section{PERFORMING ORGANIZATION NAME(S) AND ADDRESS(ES)}

National Aeronautics and Space Administration

John H. Glenn Research Center at Lewis Field

Cleveland, Ohio 44135-3191
8. PERFORMING ORGANIZATION REPORT NUMBER

E-13936

\section{SPONSORING/MONITORING AGENCY NAME(S) AND ADDRESS(ES)}

National Aeronautics and Space Administration

Washington, DC 20546-0001
10. SPONSORING/MONITORING AGENCY REPORT NUMBER

NASA TM-2003-212348

AIAA-2003-2285

\section{SUPPLEMENTARY NOTES}

Prepared for the 21st International Communication Satellite System Conference (ICSSC) and Exhibit cosponsored by the American Institute of Aeronautics and Astronautics and the Institute of Electronics, Information and Communication, Yokohama, Japan, April 15-19, 2003. Muli Kifle, Monty Andro, Quang K. Tran, and Gene Fujikawa, NASA Glenn Research Center; Pong P. Chu, Cleveland State University, Cleveland, Ohio 44115. Responsible person, Muli Kifle, organization code 5650, 216-433-6521.

12a. DISTRIBUTION/AVAILABILITY STATEMENT

12b. DISTRIBUTION CODE

Unclassified - Unlimited

Subject Category: 17

Distribution: Nonstandard

Available electronically at http://gltrs.grc.nasa.gov

This publication is available from the NASA Center for AeroSpace Information, 301-621-0390.

13. ABSTRACT (Maximum 200 words)

Future science missions will require the use of multiple spacecraft with multiple sensor nodes autonomously responding and adapting to a dynamically changing space environment. The acquisition of random scientific events will require rapidly changing network topologies, distributed processing power, and a dynamic resource management strategy. Optimum utilization and configuration of spacecraft communications and navigation resources will be critical in meeting the demand of these stringent mission requirements. There are two important trends to follow with respect to NASA's (National Aeronautics and Space Administration) future scientific missions: the use of multiple satellite systems and the development of an integrated space communications network. Reconfigurable computing and communication systems may enable versatile adaptation of a spacecraft system's resources by dynamic allocation of the processor hardware to perform new operations or to maintain functionality due to malfunctions or hardware faults. Advancements in FPGA (Field Programmable Gate Array) technology make it possible to incorporate major communication and network functionalities in FPGA chips and provide the basis for a dynamically reconfigurable communication system. Advantages of higher computation speeds and accuracy are envisioned with tremendous hardware flexibility to ensure maximum survivability of future science mission spacecraft. This paper discusses the requirements, enabling technologies, and challenges associated with dynamically reconfigurable space communications systems.

14. SUBJECT TERMS

Space communication 15. NUMBER OF PAGES 12

\begin{tabular}{|c|c|c|}
\hline $\begin{array}{c}\text { 17. SECURITY CLASSIFICATION } \\
\text { OF REPORT } \\
\text { Unclassified }\end{array}$ & $\begin{array}{c}\text { 18. SECURITY CLASSIFICATION } \\
\text { OF THIS PAGE } \\
\text { Unclassified }\end{array}$ & $\begin{array}{c}\text { 19. SECURITY CLASSIFICATION } \\
\text { OF ABSTRACT } \\
\text { Unclassified }\end{array}$ \\
\hline
\end{tabular}

